\title{
Validation of a Georgian language headache questionnaire in a population-based sample
}

\author{
Maka Kukava • Anna Dzagnidze - Marina Janelidze - Eka Mirvelashvili • \\ Mamuka Djibuti - Guenther Fritsche · Rigmor Jensen - Lars J. Stovner • \\ Timothy J. Steiner $\cdot$ Zaza Katsarava
}

Published online: 19 February 2008

(C) Springer-Verlag 2008

\section{Erratum to: J Headache Pain (2007) 8:321-324 DOI 10.1007/s10194-007-0423-6}

Unfortunately the name of one author, Marina Janelidze, was omitted and the authors' affiliations were rendered wrongly. The correct data are given here.

M. Kukava · A. Dzagnidze · M. Janelidze

Department of Neurology, Tbilisi Medical University, Tbilisi, Republic of Georgia

The online version of the original article can be found under doi:10.1007/s10194-007-0423-6.

M. Kukava · A. Dzagnidze · M. Janelidze

Department of Neurology, Tbilisi Medical University, Tbilisi,

Republic of Georgia

E. Mirvelashvili

Department of Epidemiology, Tbilisi Medical University,

Tbilisi, Republic of Georgia

M. Djibuti

Partnership in Research and Action for Health, Tbilisi, Georgia

G. Fritsche $\cdot$ Z. Katsarava $(\bowtie)$

Department of Neurology, University of Essen, Essen, Germany

e-mail: zaza.katsarava@uni-due.de

R. Jensen

Danish Headache Center, Glostrup University, Copenhagen,

Denmark

L. J. Stovner

Norwegian National Headache Centre, Trondheim University

Hospital, Trondheim, Norway

T. J. Steiner

Division of Neuroscience and Mental Health, Imperial College

London, London, UK
E. Mirvelashvili

Department of Epidemiology, Tbilisi Medical University, Tbilisi, Republic of Georgia

\section{Djibuti}

Partnership in Research and Action for Health, Tbilisi, Georgia

G. Fritsche $\cdot$ Z. Katsarava $(\square)$

Department of Neurology, University of Essen, Essen, Germany

E-mail: zaza.katsarava@uni-due.de

Tel.:+49-201-7232467

Fax: +49-201-7235919

R. Jensen

Danish Headache Center, Glostrup University, Copenhagen, Denmark

\section{L.J. Stovner}

Norwegian National Headache Centre, Trondheim University Hospital, Trondheim, Norway

\section{T.J. Steiner}

Division of Neuroscience and Mental Health, Imperial College London, London, UK 